\title{
Paper Chemistry: Past to Present - Process Engineering for Advanced Chemistry Lessons
}

\author{
Laura Bögge, Marco Reinmold, Arnim Lühken* \\ Department of Chemistry Education, Goethe-University, Frankfurt/ Main, Germany \\ *Corresponding author: luehken@chemie.uni-frankfurt.de
}

Received January 02, 2019; Revised February 16, 2019; Accepted March 20, 2019

\begin{abstract}
Paper is an omnipresent and everyday composite material. However, not all papers are alike. Different kinds of paper have characteristics specific to the respective application area which are modified by the use of different paper additives in paper production. Because those paper products are an integral part of the students' everyday lives, adequate model experiments have been developed that enable the students to reproduce complex paper production processes in chemistry class. This article therefore presents two reliable hands-on experiments that show the history of paper gluing (experiment $\mathrm{I}$ ) as well as the use and detection of polyvinyl alcohols as typical sizing agent of different kinds of paper (experiment II). Both experiments primarily use easily accessible everyday materials, which from a didactic perspective again create an everyday reference for the students. From an organizational and experimental perspective the use of everyday materials results in an inexpensive and environmentally friendly lab work with low safety-risks, so that the experiments make a valuable contribution to the introduction of paper chemistry for advanced chemistry teaching in secondary schools.
\end{abstract}

Keywords: paper chemistry, paper gluing, paper additives, model experiments, hands-on experiments

Cite This Article: Laura Bögge, Marco Reinmold, and Arnim Lühken, "Paper Chemistry: Past to Present - Process Engineering for Advanced Chemistry Lesso." World Journal of Chemical Education, vol. 7, no. 2 (2019): 84-89. doi: 10.12691/wjce-7-2-7.

\section{Introduction}

The history of human culture is strongly linked to the medium of paper. In Central Europe it has been used as a data carrier for the printed image since the 14th century, followed by its use for the printed word through the invention of letterpress printing by Gutenberg in the second half of the century. Due to its flexibility and lightness, it served as an important documentation medium for trade and thereby replaced clay and wax tablets. Since then, more and more areas of application emerged. From writing and printing papers, hygienic papers to packaging material, paper now has an omnipresence and relevance to everyday life that people oftentimes are not actively aware of. Hardly any student will associate the wet cleaning tissue and the packaging cardboard with the same raw material. This immense relevance can be demonstrated in chemistry class, for example by addressing specific characteristics of several types of paper, like the ability to label its surface or its wet or dry strength. To change and improve these characteristics, papers have been glued (sized is used equally) over the years with various sizing agents and are treated with so-called paper additives in various process steps of paper production. In this way, the properties of the paper are adapted to the particular application area and its needs. The underlying large-scale industrial processes are highly complex, multiple sub-steps often run simultaneously in one single production step. In order to be able to illustrate individual chemical processes in chemistry class, reliable and didactically valuable model experiments have been developed and tested. Experiment I is initially concerned with historically grown processes of paper surface sizing including the hydrophobization of banknotes, experiment II deals with paper additives. One of these additives are polyvinyl alcohols which are mainly used in the paper pulp as dry strength agent to glue the paper and make it greaseproof. In this second experiment, the students can detect different concentrations of polyvinyl alcohols in different kinds of paper and cardboard, as they form different colored complexes with boric acid iodide solution, depending on their concentration.

Both experiments are therefore suitable for teaching the application of natural and synthetic macromolecules as well as complex chemistry using paper as an example. All experiments are mainly carried out with everyday materials. They can be done with little preparation, inexpensively, safely and environmentally friendly.

\section{History of Paper Gluing}

Since the invention of paper, it has been glued with various sizing agents to improve its writability. From the 7th century, Arabs glued their paper with starch solution for their calligraphic art of writing. To achieve 
parchment-like characteristics, Europeans in the 13th century started treating their paper with animal glue, which mainly consists of collagen. At the beginning of the 19th century, Illig invented the cheaper gluing with resin acids, which were a low-cost waste product of the oil industries turpentine production from tree resins [1]. Ever since, techniques for paper gluing continued to evolve. Newer products make it possible to produce almost hydrophobic papers by gluing the paper fibers with stearic acid that is first saponified and then fixed to the fiber with aluminium ions.

Within experiment I the students follow this historical path of knowledge and reproduce the corresponding processes. Therefore they glue paper with (a) starch solution (b) collagen solution, which in this model-experiment is obtained from gelatin (c) abietic acid, which is the main component of resin acids in colophony and (d) sodium stearate solution to produce hydrophobic play money. In experiment (c) and (d), alum solution is additionally required as a fixing salt to the fiber.

\subsection{Experiment I}

Materials: Heating plate with magnetic stirrer, stirring fish, $4 \times 50 \mathrm{ml}$ beaker, $100 \mathrm{ml}$ beaker, $200 \mathrm{ml}$ beaker, 50 $\mathrm{ml}$ Erlenmeyer flask, 5 petri dishes, tweezer, 5 filter papers, hairdryer, various pens (e.g. ink roller, fineliner and highlighter) Chemicals: Potato starch, leaf gelatin, sodium stearate, colophony, sodium hydroxide, ethanol, distilled water, saturated alum solution $\left(\mathrm{KAl}\left(\mathrm{SO}_{4}\right)_{2}\right)$

\subsubsection{Experimental Instructions}

Preparation of the required solutions: (a) for the starch solution, $0.25 \mathrm{~g}$ of potato starch with $50 \mathrm{ml}$ of water are heated until just before boiling. The hot to warm starch solution is then transferred into a petri dish. One of the filter papers is immediately immersed in the solution, drained and dried with a hairdryer. (b) The same procedure is used for gluing with collagen solution. The collagen is obtained by dissolving 2 sheets of gelatin (approx. $3.3 \mathrm{~g}$ ) in $150 \mathrm{ml}$ distilled water during heat supply and stirring. (c) To glue the paper with abietic acid, colophony is saponified. The resin acids of colophony (mainly) consist of abietic acid which is then saponified to sodium abietate and other resinates that are water-soluble. Therefore $1 \mathrm{~g}$ of colophony is dissolved in $10 \mathrm{ml}$ ethanol in an Erlenmeyer flask while heating and stirring on a heating plate. Afterwards $10 \mathrm{ml}$ of sodium hydroxide solution $(w=25 \%)$ are added and heated to boiling while stirring. In this step two phases are formed. When the lower phase has almost evaporated, the Erlenmeyer flask is removed from the heating plate. After cooling, 2 spatula tips (approx. $0.5 \mathrm{~g}$ ) of sodium abietate from the obtained colophony soap are dissolved in $20 \mathrm{ml}$ water. This solution is transferred into a petri dish and the filter paper soaked with the sodium abietate solution. The drained paper is then turned in a petri dish with saturated alum solution, drained again and dried with a hairdryer. (d) To glue the paper with stearic acid, $0.5 \mathrm{~g}$ of sodium stearate are dissolved in $20 \mathrm{ml}$ distilled water while stirring and heating. The hot sodium stearate solution is transferred into a petri dish. The filter paper is immediately soaked with the solution, drained, also turned over in saturated alum solution, drained again and dried with a hairdryer. It is possible to replace sodium stearate with curd soap with a high concentration of stearates.

In order to test the sizing effect of the different solutions, the dried filter papers are marked with various water-based pens. The results are shown in Figure 1.

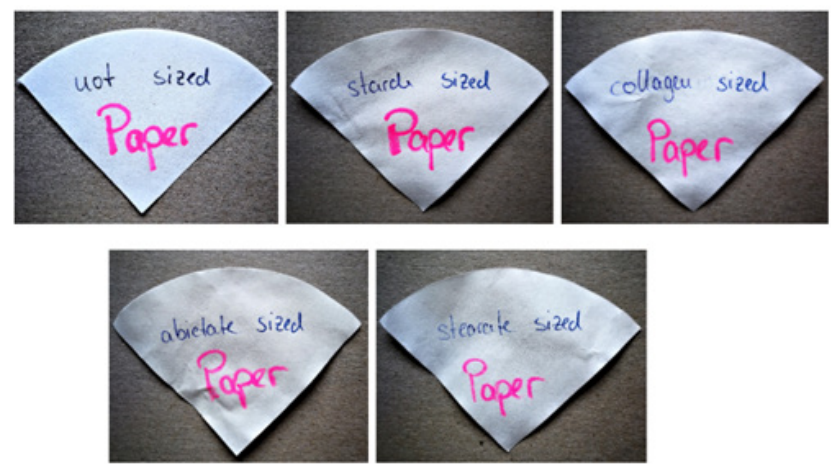

Figure 1. Sizing effect of the tested sizing agents

\subsubsection{Evaluation}

(a) The polysaccharides of starch are solvated by water molecules. The hydroxyl groups of the starch molecules then interact with the cellulose fibers of the paper pulp via hydrogen bonds. The so-called webbed effect (Figure 2) strengthens the fiber-fiber bonds formed at the crossing points of the cellulose fibers [2].

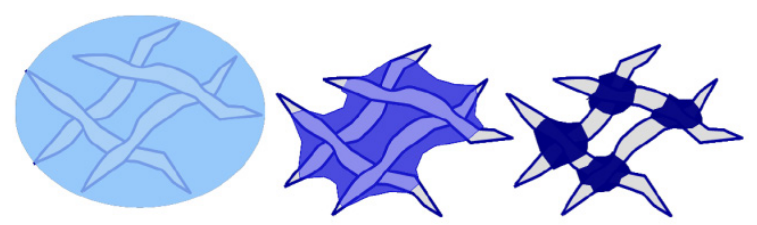

Figure 2. Representation of the webbed effect [3]

The starch remains in the fiber fleece of the pulp. As the paper dries and the water evaporates, the starch concentration in the fiber fleece increases and becomes denser at the fiber-fiber crossing points. Further hydrogen bonds are formed between the starch molecules and the cellulose building blocks of the fibers (Figure 3). The result is a starch skeleton that cross-links the fibers, stabilizes the fiber-fiber bonds and thus increases the strength of the paper: the paper is glued.

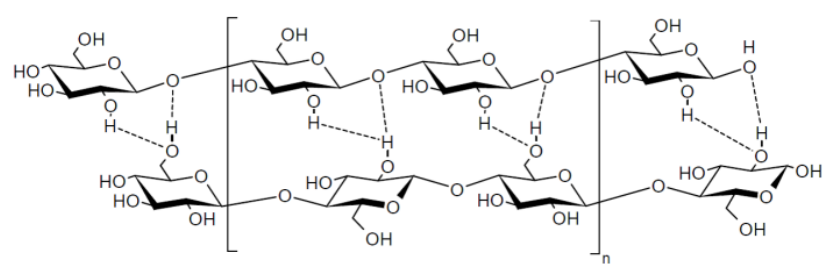

Figure 3. Interactions of amylose (top) with cellulose (bottom)

(b) Analogous to starch, hydrolyzed collagen is also solvated by water molecules. Within this gelatin sol, the water molecules interact with the polar groups of the collagen structure, whereby the protein fractions of the gelatin can more or less move freely. When the mixture cools down, the protein fractions cross-link threedimensionally to form a spatial structure: the gelatin gels 
[4]. The reinforcement of the paper structure by the formation of hydrogen bonds can also be assumed, since the protein fractions of collagen are composed of polypeptides with G-X-Y sequences. Glycine is usually found at location $G$, proline at location $X$ and 4hydroxyproline at location $\mathrm{Y}$, so each sequence has at least one polar amino acid [5]. In addition, the oxygen of the peptide bonds is negatively polarized. Finally, these polar groups can build up hydrogen bonds to the hydroxyl groups of the cellulose fibers (Figure 4). Again, the webbed effect strengthens the fiber-fiber bonds in the cellulose skeleton of the paper.

(c) By immersing the filter paper in water-soluble sodium abietate, the abietate gets in contact with the paper pulp. The abietate as well as other resinates can now attach to hydroxyl groups of the cellulose fibers via hydrogen bonds. In order to increase the adhesion, alum is used as a fixing salt. Aluminium ions therefore form a complex with abietate and hydroxyl groups of the cellulose fiber. This way the resin acid is fixed to the cellulose fiber (Figure 5).

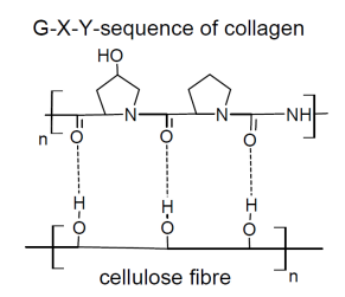

Figure 4. Interactions of collagen with cellulose

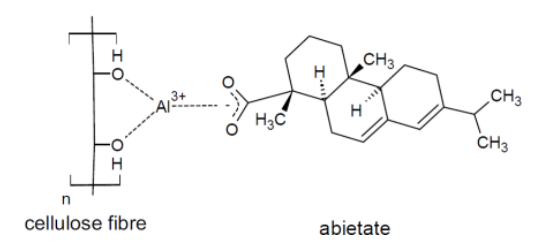

Figure 5. Complexation of abietate to cellulose via $\mathrm{Al}^{3+}$ ions

(d) The sodium stearate dissolves in water by heating, whereby the stearate together with the cellulose fiber and the alum solution forms an aluminium complex and is thus fixed to the cellulose fiber (Figure 6).

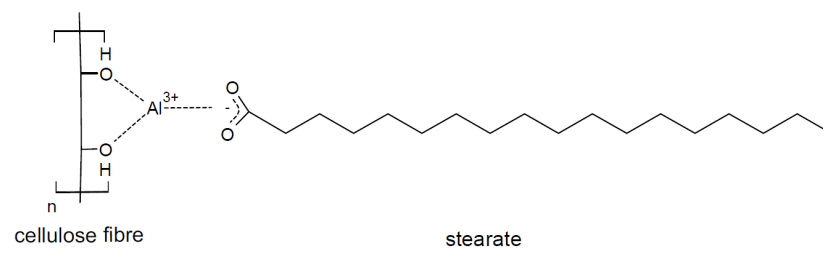

Figure 6. Complexation of stearate to cellulose via $\mathrm{Al}^{3+}$ ions

All the solutions used are sizing agents that seal the surface of the paper. If the dried, impregnated papers are now marked with different water-based pens, the paper fibers get penetrated differently depending on the viscosity and application thickness of the dyes as well as the degree of gluing and hydrophobization.

In Figure 1 it becomes visible that starch also is a dry strength agent. This effect results from the fact that, due to the polarity of the water molecule, hydrogen bonds between water and hydroxyl groups of polysaccharides are stronger than hydrogen bonds between hydroxyl groups of the starch and cellulose. The latter bonds can therefore easily be cleaved by water molecules and removed from the fiber. As a result, the water in the dye of the pencils dissolves the starch, which reduces the sizing effect and allows the dye to penetrate better into the paper. It is not wet-strength. Similar to starch, collagen is also a dry strength agent, since the hydrogen bonds between collagen and cellulose can also be cleaved by water molecules.

For sodium abietate and the stearate solution the results are different. The abietate or stearate fills the gaps between cellulose fibers of the paper and causes a hydrophobic effect [6]. Using aluminium ions the cellulose fibers are then complexed with abietate or stearate and thus provided with hydrophobic ends. This leads on the one hand to a smooth paper surface and on the other hand to the fact that dye from the pencils can draw in less easily.

\subsubsection{Didactic Suggestions}

As mentioned in the introduction, experiment I (a-d) enables the students to follow the historical path of knowledge on the development of industrial processes for paper sizing in a modeled way and to comprehend it through the corresponding evaluation. Empirical knowledge about aluminium as fixing salt, that people already had before the time of industrialization, can now be explained chemically as well [1]. In order to internalize that acquired knowledge, the students can be given the task to research differences and analogies in the industrial production steps to the processes they learned in the experiment.

The etymology of the term glue can be addressed as well since its original meaning refers to gluing cellulose fibers in the pulp by animal glue containing mainly collagen [1]. In the experiment, collagen is obtained from gelatin [4]. This networking of chemistry with everyday life materials shows that chemistry is not an isolated science. Instead, it demonstrates the variability of everyday products due to their chemical properties. The same applies to colophony, available from electronics retailers and its chemical modification by saponification. The further use of the substance demonstrates the diversity of its application in everyday contexts. Today, for example, strings of string instruments as well as the surface of handballs are rubbed with colophony to increase adhesion; climbers often rub their hands with it as well.

The students experience an enormous technical relevance of these developed processes for modern paper production. For example aluminium stearate is used to make paper surfaces hydrophobic [7]. To demonstrate this effect in class, a reference to banknotes is particularly suitable, as their washing out is prevented by hydrophobization. This can be illustrated with solution (d) and with play money instead of filter paper. Figure 7 shows the change in the structural integrity of the paper when water penetrates the fibers. Water-repellent paper retains its structure. If water can penetrate, the paper will soften, hang down smoothly and can easily be torn. Figure 8 moreover shows the opacity of impregnated and non-impregnated paper in front of a dark background.

In the sense of an everyday life oriented teaching, the teacher could refer to a media outcry of the vegan 
population of Great Britain: Newly issued 5 pound sterling banknotes are treated with beef tallow. Vegan supermarkets then refused to accept the banknotes. The company producing the banknotes then assured that no animal ingredients would be used in production. The SUN magazine finally published an article stating that the material used to impregnate the banknotes was stearic acid, a synthetically modified component of beef tallow [8]. The students could follow the discussion on the internet.

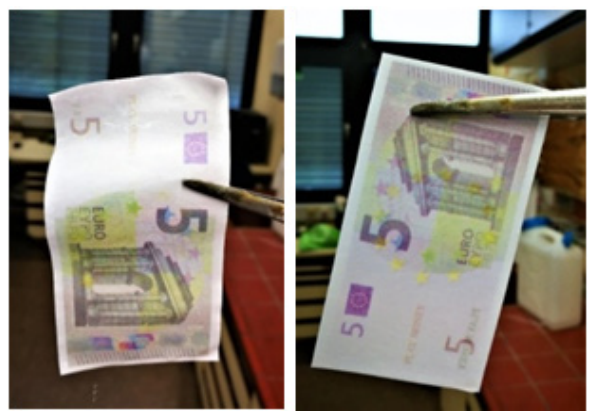

Figure 7. Hydrophobic effect of sodium stearate. Left: banknote glued with sodium stearate, right: non-glued banknote, both soaked in water

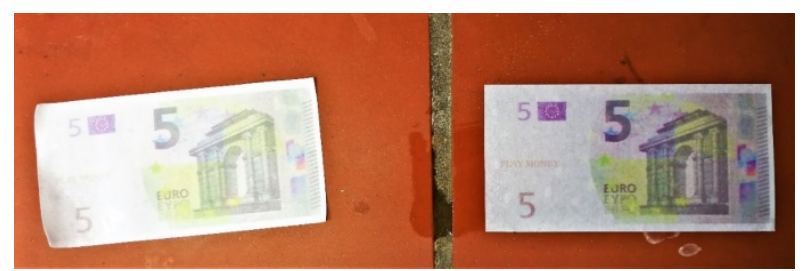

Figure 8. Opacity of an impregnated (left) and non-impregnated banknote (right)

\section{Polyvinyl Alcohols as Paper Additive}

Polyvinyl alcohols (PVA) are used in the paper industry as dry strength agent in a large number of papers. They can be detected either directly in the paper or in hot water extracts of the paper. The experiment described below presents a clear detection for PVA in hot water extracts of different paper and cardboard. Moreover different concentrations of PVA in different types of paper can be detected since they form light green to deep blue complexes with boric acid iodide solution depending on the concentration of PVA in the extract. The use of boric acid in class is permitted without restriction due to its low concentration in this experiment [9].

\subsection{Experiment II}

Materials: 2 × $200 \mathrm{ml}$ beaker, $500 \mathrm{ml}$ beaker, $50 \mathrm{ml}$ plastic beaker with screw cap, heating plate with magnetic stirring function, stirring fish, 3 plastic pipettes, test tube holder, 10 test tubes, 5 large test tubes, Bunsen burner, tripod material, crucible tongs, paper types shown in Table 1. Chemicals: Aqueous boric acid solution $(c=0.5-\mathrm{mol} / \mathrm{l})$, iodine, potassium iodide, $\alpha$-Amylase, distilled water, PVP iodine ointment (PVP-I), sodium thiosulfate.

\subsubsection{Experimental Instruction}

(a) $0.063 \mathrm{~g}$ of iodine and $0.10 \mathrm{~g}$ of potassium iodide are dissolved in $100 \mathrm{ml}$ of boric acid solution under stirring and low heat. A boric acid iodide solution (BS-I) is obtained. (b) In another beaker, two heaped spatula tips of PVP-I are dissolved in $100 \mathrm{ml}$ of water. (c) For a solution of $\alpha$-amylase, $1 \mathrm{~g}$ of $\alpha$-amylase is dissolved in $40 \mathrm{ml}$ of water in the plastic beaker.

As pre-tests, a drop of BS-I (a) and of PVP-I (b) are given directly on each tested paper. The color intensities in the pre-samples may already indicate the presence of PVA. However, the pre-tests are not unambiguous since starch can interfere with the experiment and first has to be removed by $\alpha$-amylase. Therefore hot water extracts are prepared from the paper types. The papers are cut into $1 \mathrm{~cm}$ pieces, filled into large test tubes and covered with distilled water. The test tubes are then heated above the Bunsen burner, while evaporating water is added. The hot water extracts are then decanted. For PVA detection, $1 \mathrm{ml}$ of each hot water extract is given into two test tubes, labelled and mixed with one drop each of the $\alpha$-amylase solution (c). The test tubes are heated in a water bath for $15 \mathrm{~min}$ at $40{ }^{\circ} \mathrm{C}$ and then placed in the test tube rack. For each extract, one of the two test tubes is mixed with $1 \mathrm{ml} \mathrm{BS}-\mathrm{I}$ solution (a) and the other with $1 \mathrm{ml}$ PVP-I solution (b). The results are shown in Table 1 and Figure 9 - Figure 11.

Table 1. Detection of PVA and Starch in Papers (brand in italics)

\begin{tabular}{|l|c|c|c|c|}
\hline $\begin{array}{r}\text { detection } \\
\text { papent type }\end{array}$ & + BS-I & + PVP-I & $\begin{array}{c}\text { extract }+ \\
\alpha \text {-amylase }+ \\
\text { BS-I }\end{array}$ & $\begin{array}{c}\text { extract }+ \\
\alpha \text {-amylase }+ \\
\text { PVP-I }\end{array}$ \\
\hline $\begin{array}{l}\text { self-made } \\
+ \text { PVA }\end{array}$ & dark blue & rose-violet & dark blue & yellow \\
\hline $\begin{array}{l}\text { self-made } \\
\text { - PVA }\end{array}$ & blue & $\begin{array}{c}\text { soft } \\
\text { light blue }\end{array}$ & yellow & yellow \\
\hline cardboard (Ikea) & dark blue & light blue & dark blue & yellow \\
\hline $\begin{array}{l}\text { sandwich paper } \\
\text { (Toppits) }\end{array}$ & dark blue & dark blue & yellow & yellow \\
\hline $\begin{array}{l}\text { play money } \\
\text { (Simba) }\end{array}$ & $\begin{array}{c}\text { dark blue } \\
\text { to violet }\end{array}$ & blue-violet & green & yellow \\
\hline
\end{tabular}

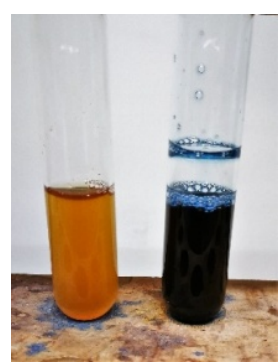

Figure 9. Left: paper extract with $\alpha$-amylase + PVP-I. Right: paper extract with $\alpha$-amylase + BS-I

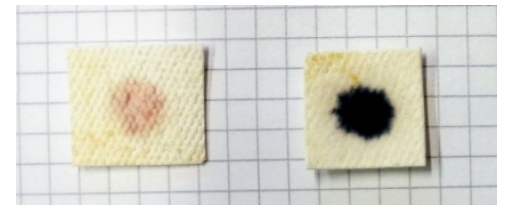

Figure 10. PVA-glued paper with PVP-I (left), with BS-I (right)

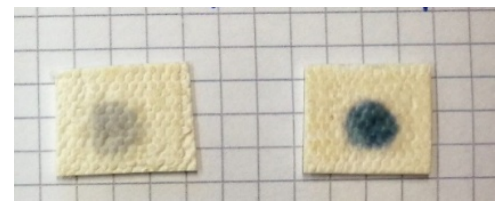

Figure 11. Non PVA-glued paper with PVP-I (left), with BS-I (right) 
Table 1 also includes results for self-made paper glued with PVA. For this purpose, $5 \mathrm{~g}$ of toilet paper are coarsely plucked, placed in a 1 liter beaker with $250 \mathrm{ml}$ of distilled water and then placed in a glass container. After adding water, the paper is mixed for approx. 3 minutes with a hand mixer to make paper pulp. Half of the pulp is then mixed with $15 \mathrm{~g}$ PVA adhesive, which has been solvated in $50 \mathrm{ml}$ water while stirring. The paper is then filled into a plastic tub, scooped with a grid, dried and smoothed with an iron. For comparison, the other half of the pulp is used to produce a paper without PVA.

\subsubsection{Evaluation}

Polyvinyl alcohols are polymers consisting of polymerized ethenols. In industry, PVA are produced by polymerization of vinyl acetate and subsequent saponification of the polyvinyl acetate. PVA have one functional hydroxyl group per vinyl unit. Analogous to the hydroxyl groups of the glucose units in cellulose and amylose, this group can form hydrogen bonds or can be esterified again, which is why PVA are water-soluble. By linking the cellulose fibers within the polymer, PVA exhibit a sizing effect [6]. They are added directly to the pulp, whereby such mass sizing modifies the paper structure in a way that water cannot penetrate into the paper fibers so easily. They are also used to make papers greaseproof.

In the hot water extract BS-I and PVA form green to blue complexes of PVA and polyiodide ions. The boric acid solution thereby has a stabilizing effect by cross linking PVA chains by esterification. This reduces the distance between the polymer chains and limits its mobility [10]. Depending on the concentration of PVA in the extract, either a didiol complex (Figure 12) or a monodiol complex (Figure 13) is formed. In aqueous solutions the formation of monodiol complexes is assumed [11]. However, the formation of a didiol complex is not excluded [12].

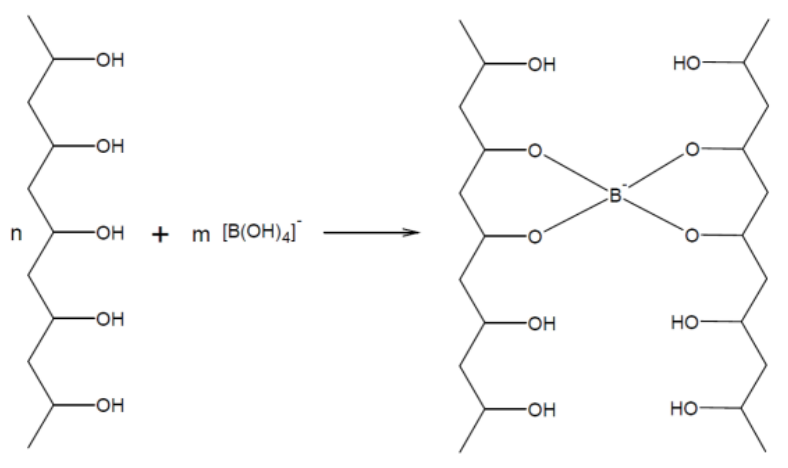

Figure 12. Didiol complex

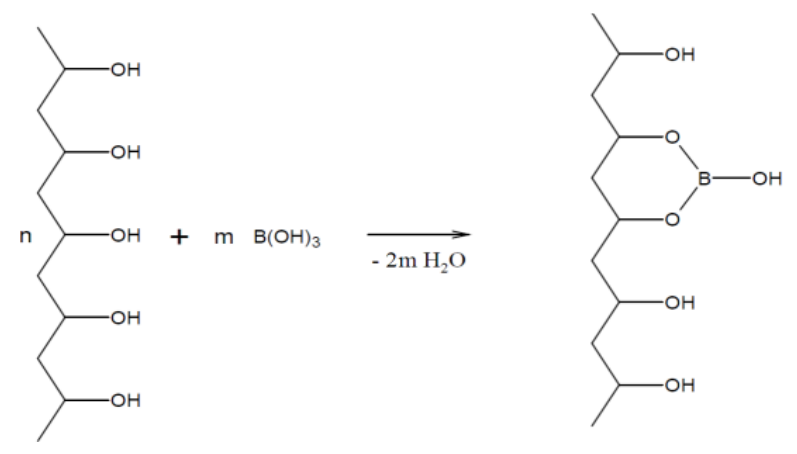

Figure 13. Monodiol complex
The coloration of the complex is determined by the PVA $\mathrm{I}_{5}{ }^{-}$ions in aqueous solution and $\mathrm{I}_{3}{ }^{-}$ions in saturated solution [13]. The complexes are stabilized by charge transfer mechanisms. The polyiodide ion thereby serves as electron acceptor and its ligands, the oxygen atoms of the hydroxyl groups in the PVA, as electron donor. With increasing complex formation, the charge transfer increases and the emission spectrum of the PVA-iodine-complex shifts from green (low concentration) to blue (high concentration) [13].

Starch can interfere with the experiment as the polyiodide ions become embedded in the helix of the amylose, forming a blue-violet polyiodide-starch complex [14]. In order to completely remove the starch from the hot water extract, the paper extract is first mixed with $\alpha$-amylase and then with BS-I reagent. PVA detection from paper extract mixed with $\alpha$-amylase is considered as clear detection, since the enzyme completely converts the starch into oligo and simple sugars [15]. To test the sample for the presence of starch molecules, PVP-I with $\alpha$-amylase is added to the hot water extract in the absence of boric acid. A yellow coloration verifies the absence of starch in the extract.

\subsubsection{Didactic Suggestions}

Through the experiment, the students learn a simple method for detecting PVA in different packaging papers. PVA can not only be detected in the packaging but is also contained as a food additive with the European label E 1203 [16] in products consumed by the students. Analogous to the first experiment, reference can be made between chemistry as a scientific discipline and industry to the students' life. In this way, a critical examination of the use and production of everyday paper products can be encouraged, and the students can be sensitized to environmental issues. For example, research on recycling processes can be carried out and discussed against the background of sustainability of raw materials, product quality control and the increasing use of paper additives due to the deteriorated fiber material of recycled paper.

It should be mentioned that the students can also use yeast to split the starch in the hot water extract. Yeast is available in any supermarket as a freeze-dried product and again shows the students how to use everyday products for chemical analysis. From biology class they are familiar with its properties, applications and the processes involved in yeast fermentation. In this way, the experiment enables cross-disciplinary references and again makes chemistry tangible as a non-isolated science. However, the detection of PVA in an extract mixed with yeast is not clear because boric acid inhibits the growth of yeast fungus [17]. Blind samples of all extracts assumed a violet to blue coloration when mixed with high amounts of BS-I solution. This is why boric acid is used to treat yeast infections of the mucous membranes. It remains at the decision of the teacher which reagent is used. For the papers to be tested, it is also recommended that the teacher makes a selection in order to obtain the intended results.

\section{Discussion}

The experiments shown are part of organic chemistry teaching in secondary school chemistry. The topic of 
complex chemistry can be linked to the use and properties of natural and synthetic macromolecules. Syllabus content of the intermediate level, such as intermolecular forces, are repeated and deepened in the same way. It can be stated that the experiments presented are model experiments for complex paper manufacturing processes that help to develop an understanding of the function of paper additives. Concrete examples like banknotes and the frequent use of everyday life materials illustrate the importance of paper production for the life of the students. The hands-on experiments can be used for a simple but didactically valuable application of paper chemistry in chemistry teaching.

\section{References}

[1] Meyer, C., Schultz, S. and Schnedmüller, B., Papier im mittelalterlichen Europa, Walter de Gruyter GmbH, Berlin, 2015.

[2] Deutschle, A. L. and Saake, B., Charakterisierung und Anwendung von kationischen Arabinoxylanen, doctoral thesis, Staats- und Universitätsbibliothek Hamburg, 2016.

[3] Gruber, E., Trockenfestigkeit; Stärke als Additiv, Duale Hochschule Karlsruhe, 2011. Available:

http://www.gruberscript.net/15Trockenfestigkeit_Staerke.pdf [Jan., 2019].

[4] Kolbe, G., Gelatine - Eigenschaften und Auswahlkriterien in der Papierrestaurierung, 2001. Available:

https://irongallink.org/images/file/pdf 8 article \%20kolbe gelati ne_iada_2001.pdf. [Aug., 2018].

[5] Calyden, J., Greeves, N. and Warren, S., Organic Chemistry, Oxford University Press, Oxford, 2001, 1141.

[6] Blechschmidt, J., Taschenbuch der Papiertechnik, Carl Hanser Verlag, München, 2013.
[7] Gesamtverband der Aluminiumindustrie e.V., AluminiumlexikonDer Werkstoff von A-Z. Available:

http://www.aluinfo.de/aluminium-lexikondetail.html?id=6\&letter=a. [Aug., 2018].

[8] Vonow, B., FAT FREE? What is tallow and why is the animal fat used to make the new plastic 10 pound and 5 pound notes? What you need to know", The Sun, 2018. Available: https://www.thesun.co.uk/money/2311208/tallow-animal-fat-newnotes/. [Aug., 2018].

[9] Lühken, A. and von der Lahr, L.-M., Borverbindungen im Schulexperiment - Die Auswirkungen der Neu-Kategorisierung von Borverbindungen auf den Experimentalunterricht, CHEMKON, 19 (4). 179-184. 2012.

[10] Ohishi, K., Itadani, T., Hayashi, T., Nakai, T. and Horii, F., Role of boric acid in the formation of poly(vinyl alcohol)-iodine complexes in undrawn Films, Polymer, 51. 687-693. 2010.

[11] Deuel, H. and Neukom, H., Über die Reaktion von Borsäure und Borax mit Polysacchariden und anderen hochmolekularen Polyoxy-Verbindungen, Agrikulturchemisches Institut der Eidgenössischen Technischen Hochschule, Zurich, 1948.

[12] Schmolinski, R., Thermoanalytische und Infrarotspektroskopische Untersuchungen am System Polyvinylalkohol / Borsäure, doctoral thesis at the University of Dortmund, 2003, 13.

[13] Tashiro, K., Kitai, H., Munirah, S., Shimazu, A. and Itou, T., Quantitative Crystal Structure Analysis of Poly(vinyl Alcohol)Iodine Complexes on the Basis of 2D X-ray Diffraction, Raman Spectra, an Computer Simulation, Macromolecules, 48 (7). 2138-2148. 2015

[14] Holleman, A. F. and Wiberg, N., Lehrbuch der Anorganischen Chemie, Walter de Gruyter, Berlin, 2007, 446.

[15] Falbe, J. and Regitz, M., Römpp Chemie-Lexikon, New York: Thieme, Stuttgart, 1995, 178-179.

[16] BLL, Liste der Lebensmittelzusatzstoffe und E-Nummern. Available: https://www.bll.de/de/lebensmittel/zusatzstoffe/listelebensmittelzusatzstoffe-e-nummern. [Aug., 2018].

[17] Kliegel, W., Bor in Biologie, Medizin und Pharmazie: Physiologische Wirkungen und Anwendung von Borverbindungen, Springer-Verlag Berlin Heidelberg GmbH, 1980, 166.

C The Author(s) 2019. This article is an open access article distributed under the terms and conditions of the Creative Commons Attribution (CC BY) license (http://creativecommons.org/licenses/by/4.0/). 